\title{
Ribonucleoprotein complexes as autoantigens
}

\section{Walther I van Venrooij and Ger JM Pruijn}

\author{
University of Nijmegen, Nijmegen, The Netherlands
}

\begin{abstract}
Many intracellular proteins and nucleic acids, that are involved in important biosynthetic pathways, are targeted by autoantibodies occurring spontaneously in the sera of patients with systemic autoimmune diseases. Frequently, the autoantigens are assembled into multicomponent complexes containing both nucleic acid(s) and proteins. Recently, progress has been made in the study of autoantigenic ribonucleoprotein complexes, the most important of which are spliceosomal ribonucleoproteins, nucleolar ribonucleoproteins, Ro/La ribonucleoproteins and complexes of aminoacyl-tRNA synthetase and tRNA. In addition to new structural and functional information, important results have been obtained on epitope spreading, as well as on a potential role for apoptosis during the development of an autoimmune response against these complexes.
\end{abstract}

Current Opinion in Immunology 1995, 7:819-824

\section{Introduction}

In a number of rheumatic diseases, the presence of the so-called antinuclear antibodies is a dominant feature. These diseases include systemic lupus erythematosus (SLE), mixed connective tissue disease (MCTD), polymyositis, scleroderma and Sjögren's syndrome. The autoantigens that are targets of such autoantibodies are often large cellular complexes that contain protein and nucleic acid components. Many autoantigenic complexes localize in the nucleus (reviewed in [1]), but autoantibodies directed to cytoplasmic organelles, such as mitochondria, centrioles and the Golgi system, have also been described. The list of interesting autoantigens targeted by antibodies found in patients with rheumatic diseases is steadily growing. Some autoantigens that have been cloned recently include one of the components of the Mi-2 autoantigen, a large dermatomyositis-specific antigenic complex [2], 56K/Annexin XI [3], PCM-1, a $228 \mathrm{kDa}$ centrosome autoantigen [4], and CENP-A, a histone-like centromere autoantigen [5].

The types of autoantibody that occur most frequently, however, are directed to DNA-protein complexes (DNPs) or RNA-protein complexes, ribonucleoproteins (RNPs). Anti-DNP antibodies can be directed to double-stranded DNA, as well as to a large variety of proteins involved in DNA metabolism, and include targets such as histones, DNA topoisomerase I, proliferating cell nuclear antigen (PCNA), $\mathrm{Ku}$ and centromere proteins $[1,6,7]$. The anti-RNP antibodies can be directed to a variety of RNAs (28S IRNA, U1 snRNA or tRNA [8]), as well as to proteins associated with these RNAs (ribosomal proteins, U snRNP proteins and tRNA synthetases [6]).

These autoantibodies have two striking, and most interesting, characteristics. First, a large number of them are disease specific (reviewed in [7]); therefore, the presence of a certain 'marker' autoantibody in a patients' serum may help the clinician considerably in reaching a diagnosis. Second, some autoantibody specificities appear to be present very early in disease, long before a clinical diagnosis has been reached. In such cases, an antibody profile can be helpful in differentiating the future development of a certain type of disease (reviewed in [9]).

In this short review, we will discuss primarily recent findings concerning the RNP autoantigens in order to provide insight into the recent progress of this field. For additional information, the reader is referred to some complementary reviews on autoantigens $[1,6,7]$.

\section{Spliceosomal RNPs}

Spliceosomes, large nuclear complexes involved in the processing of pre-mRNA, have been shown to contain a set of so-called small nuclear ribonucleoprotein particles (snRNPs), which contain both RNA and protein molecules, as well as non-snRNP proteins in addition

\footnotetext{
Abbreviations

DNP_DNA-protein complex; hnRNP_heterogeneous nuclear RNP; MCTD-mixed connective tissue disease; MRP-mitochondrial RNA processing; PKR-double-stranded RNA-activated protein kinase;

RA - rheumatoid arthritis; RNP_ribonucleoprotein; SLE-systemic lupus erythematosus;

snoRNA —small nucleolar RNA; snRNA_-small nuclear RNA; snRNP—small nuclear ribonucleoprotein particle.
} 
to the pre-mRNA. Most of the snRNPs, and several additional proteins, have been shown to be targeted by autoantibodies in patients with rheumatic diseases [10]. Autoantibodies directed against snRNPs occur predominantly in sera of patients with SLE or MCTD. One particular prevalent antibody in MCTD is called anti-U1 snRNP, which is directed to one or more of the specific proteins, U1A, U1C and U1-70K, contained in the U1 snRNP complex. A related antibody is found predominantly in SLE patients, and is called anti-Sm after the code name of the patient serum used in the study that first described this antibody system. Anti-Sm antibodies are directed to the common (or Sm) proteins $\mathrm{B}^{\prime} / \mathrm{B}$ and $\mathrm{D}_{1-3}$ present in all major $\mathrm{U}$ snRNP complexes. The proteins $B^{\prime} / B$ and $D_{1-3}$ share at least one Sm-antigenic epitope, as demonstrated by the cross-reaction of anti- $\mathrm{B}^{\prime} / \mathrm{B}$ antibodies with the $\mathrm{D}$ proteins, and vice versa. Sequence comparison has revealed that all the known $\mathrm{Sm}$ proteins share two evolutionarily conserved structural sequence motifs, which might explain their immunological cross-reactivity $\left[11^{\bullet}, 12^{\bullet}\right]$. Although the most important autoimmunizing $\mathrm{Sm}$ epitopes are yet to be identified, the fact that both polyclonal and monoclonal anti-Sm antibodies cross-react with various core proteins suggests that they share common structural elements. It is thus possible that the $\mathrm{Sm}$ motifs comprise, at least in part, one or more $\mathrm{Sm}$ B-cell epitopes [12॰].

Other major antigenic components of spliceosomes are proteins contained in heterogeneous nuclear RNP (hnRNP) complexes. In particular, autoantibodies directed to the abundant hnRNP-A1 and hnRNP-A2 proteins can often be found in sera from patients with rheumatoid arthritis (RA), SLE and MCTD [13].

\section{Nucleolar RNPs}

The nucleolus contains a large number of autoantigens that are targeted by autoantibodies that are produced by patients with a connective tissue disease, mostly scleroderma $[1,6,7]$. A dynamic and expanding field of research is the study of the growing number of small nucleolar RNAs (snoRNAs), each of them presumably associated with common proteins (e.g. fibrillarin) and specific, as yet unidentified, proteins. Although some of these RNAs are coded for by independent genes transcribed by RNA polymerase II (e.g. snoRNAs U3, U8 and U13) or RNA polymerase III (7-2/MRP RNA), most are encoded within introns of mRNA coding genes (U14-U22, and more to come [14]). The major autoantigen in these snoRNP particles is fibrillarin, a common protein indirectly associated with most of these snoRNAs. Autoantibodies directed to fibrillarin are found in patients with scleroderma, but can also be induced in certain strains of mice by treatment with mercuric chloride $\left(\mathrm{HgCl}_{2}\right)$. The epitope regions in fibrillarin recognized by the spontaneous human and toxin-induced murine autoantibodies appear to be the same, and included amino- and carboxy-terminal regions [15॰]. Given these striking similarities, it is to be expected that the murine $\mathrm{HgCl}_{2}$ model may teach us what is actually happening in the patient when autoantibody production is initiated.

$R$ Nase $\mathrm{P}$ is an endoribonuclease that processes precursor tRNA transcripts to generate their mature $5^{\prime}$ termini. Many patients with an autoimmune disease produce antibodies against a $40 \mathrm{kDa}$ protein (referred to as the Th40 antigen), which is one of the components of eukaryotic RNase $P$, as well as nucleolar 7-2 RNP, which is identical to the mitochondrial RNA processing (MRP) RNP. Reddy and coworkers [16] mapped the RNA-binding site of the $\mathrm{Th}$ antigen (presumed to be Th40) to nucleotides 20-75 near the $5^{\prime}$ end of human RNase P RNA. It was previously shown that the same antigen(s) bound to a non-homologous sequence at the $5^{\prime}$ end of 7-2/MRP RNA. Both sequences, however, are capable of assuming a similar secondary structure that corresponds to a 'cage' like structure, indicating that the major determinants for binding of Th40 are conformational and not contained in the primary structure of the RNAs.

\section{Ro/La RNPs}

Two of the main targets of autoantibodies from patients with SLE and Sjögren's syndrome are the La (SS-B) and Ro (SS-A) ribonucleoproteins (reviewed in [17]). Recently, interest in the biological and immunological properties of the La and Ro RNPs has grown markedly. The first indications of a biological function for a Ro protein have been obtained, and although La was previously only known to act in termination of RNA polymerase III transcription, evidence has also been obtained for additional function(s) of this protein in the cell.

The evolutionarily conserved $60 \mathrm{kDa}$ Ro protein component (Ro60) was found complexed with certain variant $5 \mathrm{~S}$ rRNAs in Xenopus laevis oocytes and was proposed to function in the quality control or discard pathway for $5 S$ rRNA precursors [18 $8^{\circ}$. In agreement with such a function, part of Ro60 was shown to reside in the cell nucleus, in contrast to the Ro60 contained in RoRNP complexes, which is localized exclusively in the cytoplasm [19-21]. The recent identification of a Ro60 homolog in Cacnorhabditis elegans [22.] will further aid to unravel the function of Ro60 via genetic approaches. The $52 \mathrm{kDa}$ Ro protein (Ro52) was also found in both the nucleus and cytoplasm $[19,21]$ but the majority of this protein is cytoplasmic, which is substantiated by the cytoplasmic accumulation of Ro52 observed in transfected cells that overexpress this protein [23]. The association of Ro52 with Ro RNPs remains a matter of controversy. Although Ro52 could not be detected in partially purified Ro RNPs $\left[24,25^{\circ}\right]$, the results of 
Peek et al. $\left[26^{\circ}\right]$ indicate that only a restricted number of Ro52 epitopes is accessible in Ro RNPs, implying that the recognition of Ro RNPs by anti-Ro52 antibodies is highly dependent on the specificity of the antibodies. In any case, although present in the cytoplasm, the majority of Ro52 does not seem to be stably associated with Ro RNPs.

A variant $\mathrm{Ro52}$ protein resulting from alternative splicing (exon skipping) has recently been identified ([27]; WJ van Venrooij, GJM Pruijn, unpublished data) but the physiological relevance of this variant, which appears to be ubiquitously expressed, still has to be established.

The role of the La protein in the termination of transcription by RNA polymerase III was further elaborated by Maraia et al. [28]: La was shown to mediate transcript release and to facilitate multiple rounds of transcription reinitiation by RNA polymerase III. Although $\mathrm{La}$ is believed to be localized mainly in the nucleus, several observations suggest that La may also be involved in some aspects of translation, which may be related to its stable association with the cytoplasmic Y RNAs and to a redistribution (cytoplasmic accumulation) under certain stress conditions, such as viral infection. The binding and unwinding of double-stranded RNA by La was shown to inhibit the double-stranded RNA-dependent activation of the protein kinase PKR in vitro [29]; PKR is known to be involved in the phosphorylation of the $\alpha$ subunit of protein synthesis initiation factor eIF-2. A more specialized role for $\mathrm{La}$ has been demonstrated in the translation of some viral mRNAs. La binds to the $5^{\prime}$ untranslated region of poliovirus mRNA and promotes (internal, cap-independent) initiation of translation at the correct AUG [30]. The La protein also binds to the HIV-1 leader RNA, the trans-activation response element (TAR), and alleviates translational repression by this element (cap-dependent initiation) [31॰].

La proteins from Drosophila melanoyaster and Saccharomyces cerevisiae have also recently been identified and characterized [32-34]. The gene encoding the yeast homolog of La appeared to be dispensable for viability, but at present, it can not be excluded that additional La homologs exist in yeast.

Many studies have addressed the characterization of the epitopes on the Ro and $\mathrm{La}$ proteins that are recognized by autoantibodies. In summary, multiple epitopes appear to be present on each of these proteins. Striking features of these epitopes are the discontinuity of the major Ro60 epitope(s), the apparent absence of important epitopes in the carboxy-terminal half of Ro52 $[26 \cdot 35,36]$, and the presence of a conformational epitope in the RNA-binding domain (RNP motif) of La [37]. Maternal anti-La antibodies that cross-react with laminin have been proposed to contribute to the pathogenesis of congenital heart block [38]. Recently, novel antibodies that target deproteinized hY5 RNA have been identified in the sera of patients with anti-Ro antibodies [39].

\section{Aminoacyl-tRNA synthetases}

These enzymes perform an essential function in protein synthesis by catalyzing the esterification of an amino acid to its cognate tRNA. Histidyl-tRNA synthetase is the most frequent target of autoantibodies in patients with an idiopathic inflammatory myopathy (polymyositis or dermatomyositis), but autoantibodies directed to other members of this family (alanyl-, glycyl-, isoleucyl- and threonyl-tRNA synthetase) have occasionally also been found in myositis patients $[1,6,7]$. The autoantibodies directed to His-tRNA synthetase, also called anti-Jo 1 antibodies, precede the clinical illness, and the immune response bears the hallmarks of a typical secondary immune response. Why these particular proteins are selected as targets in myositis remains unclear. Plotz and coworkers [40] mapped the B-cell epitope region that is predominantly recognized by the anti-Jo 1 antibodies and found it to be contained in the amino-terminal 60 amino acids, a region of the protein with a high $\alpha$ helical content. This finding provides further support to the hypothesis that long, charge-rich $\alpha$ helices (coiled-coils) are found more frequently in (epitope regions of) autoantigens than in other proteins. Recently [41], the cDNA sequence of human glycyl-tRNA synthetase was published. As patient antibodies directed to this autoantigen were also able to inhibit Gly-tRNA synthetase activity, just like the anti-Jo 1 antibodies inhibit His-tRNA synthetase activity, it would be interesting to see whether the B-cell epitope of this autoantigen includes a coiled-coil region as well.

\section{Why autoantibodies to RNP autoantigens?}

Additional evidence for a B-cell epitope spreading mechanism has been published by a series of elegant papers from the laboratories of Mamula and Craft (see

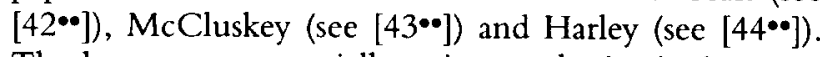
The latter paper especially points to the intriguing possibility that autoimmune diseases could be accompanied or induced by immune responses to relatively simple antigenic structures. In 1989, Habets et al. [45] showed that proline-rich sequences are cross-reacting targets of anti-Sm and anti-RNP autoantibodies. Harley and coworkers [44*0] immunized rabbits with PPPGMRPP or PPPGIRGP (single-letter code for amino acids) and observed that the animals developed high titers not only against these peptides, but also to other parts of the molecules from which these peptides were derived (i.e. the $\mathrm{Sm}-\mathrm{B} / \mathrm{B}^{\prime}$ proteins) as well as against a variety of other spliceosomal components, including the U1-70K, U1C, $\mathrm{U} 1 \mathrm{~A}$ and $\mathrm{Sm}-\mathrm{D}$ proteins. 
The structural association of the $\mathrm{La}$ and Ro proteins in Ro RNP particles in the cell might also be related to the frequent co-occurrence of autoantibodies against these proteins in patient sera. In a recent study, Topfer et al. [43*0] examined whether immunity to $\mathrm{La}$ and Ro60 autoantigens can be triggered by immunization with recombinant antigen. The data demonstrate the incomplete nature of $\mathrm{T}$-cell and $\mathrm{B}$-cell tolerance to these polypeptides in normal, healthy mice and reveal not only intramolecular spreading of the immune response, but also intermolecular spreading. Although the mechanism of intra- and intermolecular spreading is not known, it is tempting to speculate that endogenous La/Ro RNP complexes are involved. A potential role for microorganism infection in the etiopathogenesis of SLE and other related autoimmune diseases has been proposed in the past. Interestingly, immunization of rabbits with vesicular stomatitis virus $\mathrm{N}$-protein, which had previously been shown to share sequences with peptide epitopes of Ro60, not only led to an immune response to the $\mathrm{N}$-protein, but also to an anti-Ro60 autoimmune response, which is not restricted to the sequences shared with the $\mathrm{N}$-protein [46].

One very interesting study published last year called attention to the possible association of apoptosis and autoantibody production. Casciola-Rosen et al. [47*0] showed that UV irradiation of cultured human keratinocytes could induce changes consistent with apoptosis and that certain autoantigenic complexes (Ro RNPs, nucleosomes, snRNPs) accumulate in apoptotic blebs and apoptotic bodies in these dying cells. Even more interestingly, they showed in a subsequent study [48.] that one of the more important autoantigens, the $\mathrm{U} 1-70 \mathrm{~K}$ protein, is specifically cleaved in apoptotic cells. The possible implication of this work is that massive apoptosis in a genetically susceptible individual might be a mechanism via which appropriate MHC class II molecules might capture and present self-peptides that were previously cryptic. The immune response to this self-peptide may subsequently spread to other areas of the self-molecule to which the organism was previously tolerant. Indeed, such a sequence of events might explain why autoantibodies in a particular disease are directed at multiple antigens contained in the same RNP, DNP or protein-protein complex [48॰].

\section{Conclusions}

Autoantibodies occurring in patients with rheumatic diseases can be directed to a large variety of cellular complexes, either in the nucleus or in the cytoplasm. Thanks to the availability of patient antibodies, we are now able to elucidate the structure and function of these complexes in the cell. The results of many studies have clearly established that most of these autoantibodies arise as a consequence of an antigen-driven response. Nevertheless, the autoimmune response may be triggered by the presence of a certain antibody that was originally raised against a foreign microorganismal invader but that displays some self reactivity. Spreading of the anti-self response may occur under certain conditions that are still undefined, but the finding that various antigenic RNP complexes, probably modified in some way [48 ${ }^{\circ}$, seem to cluster in apoptotic structures like blebs near the membrane of apoptotic cells, which might enhance their availability to the immune system, certainly provides an attractive and testable explanation. The specific relation between the presence of a certain autoantibody specificity and a disease that is developing might thus be related to and dependent on at least three factors: first, the type of microorganism leading to cross-reactive anti-self antibody; second, the circumstances that lead to spreading of the anti-self response; and third, the fate of intracellular complexes during apoptosis.

\section{Acknowledgements}

We wish to thank all those colleagues who kindly sent us recent reprints and preprints. Although we did not have space to mention them all, they were all very useful. The research of WJ van Venrooij has been supported by financial aid from 'Het Nationaal Reumafonds' of The Netherlands and was supported, in part, by the Netherlands Foundation for Chemical Research (SON) with financial aid from the Netherlands Organization for Scientific Research (NWO). The research of GJM Pruijn has been made possible by a fellowship of the Royal Netherlands Academy of Arts and Sciences.

\section{References and recommended reading}

Papers of particular interest, published within the annual period of review, have been highlighted as:

- of special interest

- of outstanding interest

1. Van Venrooij WJ, Maini RN: Manual of biological markers of disease, Section B. Dordrecht/Boston/London: Kluwer Academic Publishers; 1994.

2. Seelig $H P$, Moosbrugger $I$, Ehrfeld $H$, Fink $T$, Renz $M$, Genth $\mathrm{E}$ : The major dermatomyositis specific Mi-2 autoantigen is a presumed helicase involved in transcriptional activation. Arthritis Rheum 1995, 38:1389-1399.

3. Misaki Y, Pruijn GJM, Van der Kemp AWCM, Van Venrooij W]: The $56 \mathrm{~K}$ autoantigen is identical to human annexin XI. J Biol Chem 1994, 269:4240-4246.

4. Balczon R, Bao L, Zimmer WE: PCM-1, a 228-kD centrosome autoantigen with a distinct cell cycle distribution. I Cell Biol 1994, 124:783-793.

5. Sullivan KF Hechenberger M Masri K: Human CENP-A contains a histone $\mathrm{H3}$ related histone fold domain that is required for targeting to the centromere. J Cell Biol 1994, 127:581-592.

6. Van Venrooij W]: Autoantigens in connective tissue diseases. In Immunology of the connective tissue diseases. Edited by Panayi GS. Dordrecht: Kluwer Academic Publisher; 1994:305-334.

7. Craft J, Hardin JA: Antinuclear antibodies. In Textbook of Rheumatology, edn 4. Edited by Kelley WN, Harris ED, Ruddy S, Sledge C. Philadelphia: Saunders Company; 1993:164-187. 
8. Hoet RM, Van Venrooij WJ: B-cell epitopes of RNA autoantigens. Mol Biol Rep 1992, 16:199-205.

9. Van Venrooij WJ, Van de Putte LB: The clinical significance of anti-nuclear antibodies in connective tissue diseases. Semin Clin Immunol 1991, 3:27-32.

10. Van Venrooij WJ, Sillekens PTG: Small nuclear RNA associated proteins, autoantigens in connective tissue diseases. Clin Exp Rheumatol 1989, 7:635-645.

11. Séraphin B: $\mathrm{Sm}$ and $\mathrm{Sm}$-like proteins belong to a large family: - identification of proteins of the $\mathrm{U} 6$ as well as the U1, U2, U4 and U5snRNPs. EMBO f 1995, 14:2089-2098.

See annotation $\left[12^{\bullet}\right]$.

12. Hermann $H$, Fabrizio $P$, Raker VA, Foulaki $K$, Hornig $H$, Brahms

- $\quad H$, Lührmann R: snRNP Sm proteins share two evolutionarily conserved sequence motifs which are involved in $\mathrm{Sm}$ protein-protein interactions. EMBO / 1995, 14:2076-2088.

This paper and $\left[11^{\circ}\right]$ are of particular interest because they show that Sm proteins share a common structural motif, which may explain their cross-reactivity. The conserved sequence motifs may help to further our understanding of how snRNPs act as autoantigens in SLE.

13. Hassfeld W, Steiner G, Studnicka-Benke A, Skriner K, Graninger $W$ Fischer I Smolen IS: Autoimmune response to the spliceosome. An immunological link between meumatoid arthritis, mixed connective tissue disease, and systemic lupus erythematosus. Arthritis Rheum 1995, 38:777-785.

14. Filipowicz $W$, Kiss $T$ : Structure and function of nucleolar SnRNPs. Mol Biol Rep 1993, 18:149-156.

15. Takeuchi K, Turley SJ, Tan EM, Pollard KM: Analysis of - the autoantibody response to fibrillarin in human disease and murine models of autoimmunity. I Immunol 1995, 154:961-971.

This paper shows not only that spontaneous human autoantibodies and murine $\mathrm{HgCl}_{2}$-induced autoantibodies recognize the same protein in the nucleolus (i.e. the snoRNP-associated protein fibrillarin) but also that they recognize a similar epitopic region on this protein. These similarities indicate that the $\mathrm{HgCl}_{2}$-induced response in the mouse could identify potential steps in the generation of human autoantibodies.

16. Liu M-H, Yuan Y, Reddy R: Human RNaseP RNA and nucleolar 7-2 RNA share conserved 'To' antigen-binding domains. Mol Cell Biochem 1994, 130:75-82.

17. Van Venrooij WJ, Slobbe RL, Pruijn GIM: Structure and function of La and Ro RNPs. Mol Biol Rep 1993, 18:113-119.

18. O'Brien CA, Wolin SL: A possible role for the 60-kD Ro - autoantigen in a discard pathway for defective 5S rRNA precursors. Cenes Dev 1994, 8:2891-2903.

Evidence is presented that Ro60 forms complexes with defective precursors of 5 S rRNA in Xenopus laevis oocytes and a role for Ro60 in the discard pathway of these RNAs is proposed. This is the first direct indication for a possible function of a Ro RNP component.

19. Simons FHM, Pruijn GIM, Van Venrooij WJ: Analysis of the intracellular localization and assembly of Ro ribonucleoprotein particles by microinjection into Xenopus laevis oocytes. I Cell Biol 1994, 125:981-988.

20. Keech CL, McCluskey J, Gordon TP: Transfection and overexpression of the human 60-kDa Ro/SS-A autoantigen in HEp-2 cells. Clin Immunol Immunopathol 1994, 73:146-151.

21. Peek R, Pruijn GJM, Van der Kemp AJW, Van Venrooij WJ Subcellular distribution of Ro ribonucleoprotein complexes and their constituents. J Cell SCi 1993, 106:929-935.

22. Van Horn DI, Eisenberg D, O'Brien CA, Wolin SL: - Caenorhabditis elegans embryos contain only one major species of Ro RNP. RNA 1995, 1:293-304.

This is the first description of Ro RNPs in invertebrate species. Its identification in a genetically tractable invertebrate will allow mutational experiments to elucidate the, as yet unknown, function of these RNPs.

23. Keech CL, Gordon TP, MCCluskey J: Cytoplasmic accumulation of the $52 \mathrm{kDa}$ Ro/SS-A nuclear autoantigen in transfected cell lines. / Autoimmun 1995, in press.

24. Kelekar A, Saitta MR, Keene JD: Molecular composition of Ro small ribonucleoprotein complexes in human cells - intracellular localization of the 60 - and $52-\mathrm{kD}$ proteins. I Clin Invest 1994, 93:1637-1644.

25. Boire G, Gendron M, Monast N, Bastin B, Menard HA: - Purification of antigenically intact Ro ribonucleoproteins; biochemical and immunological evidence that the 52-kD protein is not a Ro protein. Clin Exp Immunol 1995, 100:489-498.

In this paper, the partial biochemical purification of Ro RNPs is described. The results show that in HeLa cells, the majority of Ro52 is not stably associated with Ro RNPs.

26. Peek R, Pruijn GIM, Van Venrooij WJ: Epitope specificity - determines the ability of anti-Ro52 autoantibodies to precipitate Ro ribonucleoprotein particles. / Immunol 1994, 153:4321-4329.

The association of Ro52 with Ro RNPs is still questionable, particularly because not all monospecific anti-Ro52 sera are able to precipitate Ro RNPs. This paper describes two subsets of anti-Ro52 autoantibodies, one directed to both the non-Ro RNP-associated and the Ro RNP-associated Ro52, the other directed exclusively to the non-Ro RNP-associated Ro52 protein. The latter type of antibody will not be able to precipitate Ro RNPs.

27. Chan EKL, Di Donato F, Hamel IC, Tseng CE, Buyon JP: 52-kD SS-A/Ro: genomic structure and identification of an alternatively spliced transcript encoding a novel leucine zipper-minus autoantigen expressed in fetal and adult heart. J Exp Med 1995, 182:983-992.

28. Maraia RJ, Kenan DJ, Keene JD: Eukaryotic transcription termination factor La mediates transcript release and facilitates reinitiation by RNA polymerase III. Mol Cell Biol 1994, $14: 2147-2158$

29. Xiao QR, Sharp TV, Jeffrey IW, James MC, Pruijn GJM, Van Venrooij WJ. Clemens MI: The La antigen inhibits the activation of the interferon-inducible protein kinase PKR by sequestering and unwinding double-stranded RNA. Nucleic Acids Res 1994, 22:2512-2518.

30. Svitkin VV, Meerovitch K, Lee HS, Dholakia JN, Kenan DJ, Agol $\mathrm{VI}$, Sonenberg $\mathrm{N}$ : Internal translation initiation on poliovirus RNA: further characterization of La function in poliovirus translation in vitro. 1994, 68:1544-1550.

31. Svitkin $\mathrm{YV}$, Pause $\mathrm{A}$, Sonenberg $\mathrm{N}$ : La autoantigen alleviates - translational repression by the $5^{\prime}$ leader sequence of the human immunodeficiency virus type 1 mRNA. I Virol 1994, 68:7001-7007.

This paper describes that La, after being implicated in cap-independent internal translation initiation on poliovirus RNA (see [30]), relieves the cis-inhibitory effect of the HIV-1 TAR RNA on cap-dependent translation initiation. Melting of secondary structures (like TAR) at the $5^{\prime}$ end of these mRNAs is an attractive mechanism of stimulation of translation by La in view of its reported unwinding activity (see [29]).

32. Yoo C, Wolin SL: La proteins from Drosophila melanogaster and Saccharomyces cerevisiae: a yeast homolog of the La autoantigen is dispensable for growth. Mol Cell Biol 1994, 14:5412-5424.

33. Bai C, Li Z, Tolias PP: Der elopmental characterization of a Drosophila RNA-binding protein homologous to the human systemic lupus erythematosus-associated La/SS-B autoantigen. Mol Cell Biol 1994, 14:5123-5129.

34. Lin-Marq N, Clarkson SG: A yeast RNA binding protein that resembles the human autoantigen La. / Mol Biol 1995, 245:81-85.

35. Bozic B, Pruijn GJM, Rozman B, Van Venrooij WJ: Sera from patients with rheumatic diseases recognize different epitope regions on the 52-kD Ro/SS-A protein. Clin Exp Immunol 1993, 94:227-235.

36. Buyon IP, Slade SG, Reveille JD, Hamel JC, Chan EKL: Autoantibody responses to the native $52-\mathbf{k D a}$ SS-A/Ro protein in neonatal lupus syndromes, systemic lupus erythematosus, and Sjögren's syndrome. I Immunol 1994, 152:3675-3684.

37. Rischmueller M, McNeilage LJ, MCCluskey J, Gordon T: Human autoantibodies directed against the RNA recognition motif of La (SS-B) bind to a conformational epitope present on the 
intact La (SS-B)/Ro (SS-A) ribonucleoprotein particle. Clin Exp Immunol 1995, 101:39-44.

38. Li JM, Horsfall AC, Maini RN: Anti-La (SS-B) but not anti-Ro52 (SS-A) antibodies cross-react with laminin, a role in the pathogenesis of congenital heart block? Clin Exp Immunol 1995, 99:316-324

39. Boulanger C, Chabot B, Menard HA, Boire G: Autoantibodies in human anti-Ro sera specifically recognize deproteinized $h Y 5$ Ro RNA. Clin Exp Immunol 1995, 99:29-36.

40. Raben N, Nichols R, Dohlman J, McPhie P, Sridhar V, Hyde $C$, Leff $R$, Plotz P: A motif in human histidyl-tRNA synthetase which is shared among several aminoacyl-tRNA synthetases is a coiled-coil that is essential for enzymatic activity and contains the major autoantigenic epitope. I Biol Chem 1994, 269:24277-24283.

41. Ge Q, Trieu EP, Targoff IN: Primary structure and functional expression of human glycyl-tRNA synthetase, an autoantigen in myositis. / Biol Chem 1994, 269:28790-28797.

42. Mamula MJ, Fatenejad S, Craft I: B cells process and present -. lupus autoantigens that initiate autoimmune $T$ cell responses. f Immunol 1994, 152:1453-1461.

This interesting study shows that T-cell tolerance to snRNPs, common autoantigens in SLE and MCTD, can be broken via SnRNP-specific $B$ cells that process and present self snRNPs determinants with subsequent generation of autoreactive T cells.

43. Topfer F, Gordon T, McCluskey I: Intra- and intermolecular - spreading of autoimmunity involving the nuclear self-antigens La (SS-B) and Ro (SS-A). Proc Natl Acad Sci USA 1995, 92:875-879.

This study demonstrates the development of autoantibodies to multiple components of the La/Ro ribonucleoprotein complex in healthy, non-autoimmune mice, following initiation of immunity to a single component or a fragment thereof.

44. James JA, Gross T, Scofield RH, Harley JB: Immunoglob-. ulin epitope spreading and autoimmune disease after peptide immunization: $\mathrm{Sm}$ B/B'-derived PPPGMRPP and PPPGIRGP induce spliceosome autoimmunity. / Exp Med 1995, 181:453-461

This paper is of special interest because it shows that rabbits immunized with certain $\mathrm{Sm}-\mathrm{B} / \mathrm{B}^{\prime}$-derived peptides develop a multiple set of autoantibodies that recognize other snRNP proteins. The combined results of $\left[42^{\bullet \bullet}, 43^{\bullet \bullet}, 44^{\bullet \bullet}\right]$ show how an autoimmune response to a single region of a self-antigen could trigger intra- and intermolecular spreading to involve associated self-components.

45. Habets WI, Sillekens PTG, Hoet MH, MCAllister G, Lerner MR, Van Venrooij W]: Small nuclear RNA-associated proteins are immunologically related as revealed by mapping of autoimmune reactive B-cell epitopes. Proc Natl Acad Sci USA 1989, 86:4674-4678.

46. Huang $S$, Pan Z, Kurien BT, James JA, Harley JB, Scofield RH: Immunization with vesicular stomatitis virus nucleocapsid protein induces autoantibodies to the $60 \mathrm{kD} \mathrm{Ro}$ ribonucleoprotein particle. J Invest Med 1995, 43:151-158.

47. Casciola-Rosen LA, Anhalt G, Rosen A: Autoantigens targeted -. in systemic lupus erythematosus are clustered in two populations of surface structures on apoptotic keratinocytes. $)$ Exp Med 1994, 179:1317-1330.

An important study suggesting that potentially immunogenic cellular components (Ro RNPs, snRNPs and nucleosomes) are clustered in two distinct populations of blebs at the surface of apoptotic cells. Massive apoptosis, together with chemical modifications occurring during this process (see $\left[48^{\circ}\right]$ ), might be a mechanism to explain why certain antigenic complexes become autoantigens.

48. Casciola-Rosen LA, Miller DK, Anhalt G), Rosen A: Specific - cleavage of the 70-kDa protein component of the U1 small nuclear ribonucleoprotein is a characteristic biochemical feature of apoptotic cell death. I Biol Chem 1994, 269: $30757-30760$.

This paper shows that an important autoantigen (i.e. U1-70K) is specifically cleaved during apoptosis. A possible implication could be that previously cryptic sites of the protein could become exposed to the immune system, possible leading to an autoimmune reaction.

WJ van Venrooij and GJM Pruijn, Department of Biochemistry, University of Nijmegen, PO Box 9101, NL-6500 HB Nijmegen, The Netherlands.

WJ van Venrooij e-mail: W.Vanvenrooij@bioch.kun.nl

GJM Pruijn e-mail: G.Pruijn@bioch.kun.nl 